\title{
Geriatric Rehabilitation and COVID-19: a Case Report
}

\author{
Marine Brika $^{1} \cdot$ Maëva Bossu ${ }^{1} \cdot$ Lilian Fautrelle $^{2} \cdot$ France Mourey $^{3} \cdot$ Alexandre Kubicki $^{1,4}$
}

Accepted: 23 October 2020 / Published online: 9 November 2020

(C) Springer Nature Switzerland AG 2020

\begin{abstract}
The COVID-19 infection has particularly affected older adults. Clinical observations in this population highlight major respiratory impairment associated with the development or aggravation of the patient's frailty state. Mr. P is a 93-year-old frail patient, hospitalized after a COVID-19 infection. The assessment process of this patient has been supported by an innovative multisystemic tool developed in view of the COVID-19 clinical consequences and a systemic evaluation of motor functions by the Frail'BESTest. This process allowed a mixed clinical picture associated with significant respiratory distress (linked with acute respiratory distress syndrome) and an evident motor frailty. The care plan was developed accordingly, and four assessments were done in the same manner until Mr. P returned home. This case report allows us to see a holistic COVID-19 clinical picture, showing the different axes of clinical reasoning to enhance the rehabilitation process. Furthermore, this case report illustrates the importance of rehabilitation in the COVID-19 context.
\end{abstract}

Keywords COVID-19- Geriatric rehabilitation - Frailty - Clinical reasoning $\cdot$ Screening

\section{Introduction}

The COVID-19 pandemic targets aged adults, especially when they carry comorbidities [1]. In elderly adults, frailty corresponds to the clinical consequences of physiological function decline, involving pathological aging. Frailty is characterized by a loss of functional supplies, leading to a high risk of falls, institutionalization, and sometimes death [2]. Aged adults who survive COVID-19 could present several frailty criteria following respiratory distress and may sometimes need to spend several days in an intensive care unit. There

This article is part of the Topical Collection on COVID-19

Marine Brika

Marine.brika@hnfc.fr

1 Hôpital Nord Franche-Comté, Institut de Formation des Métiers de la Santé, Filière Kinésithérapie - Physiothérapie,

25200 Montbeliard, France

2 ToNIC, Toulouse NeuroImaging Center, UMR1214, INSERM, UPS, 31000 Toulouse, France

3 INSERM UMR1093-CAPS, UFR des Sciences du Sport, Université Bourgogne Franche-Comté, 21000 Dijon, France

4 Laboratoire de Neurosciences (EA 481), Université de Bourgogne Franche-Comté, 25000 Besancon, France are multiple clinical pictures associating respiratory and vascular consequences, bed rest effects, and medication effects in a psychological context of anxiety [3, 4].

\section{Case Description}

The case report of Mr. P aims to underline the mixed clinical picture of Acute Respiratory Distress Syndrome (ARDS) and motor frailty. This case seems highly generalizable in the pandemic context where high age and associated diseases are major causing factors of death.

On March 3, 2020, Mr. P is hospitalized for a COVID-19 infection, confirmed by a thoracic scan showing the typical ground-glass opacities (Fig. 1). His pulmonary function decreased, entailing oxygen supplementation of $15 \mathrm{~L} / \mathrm{min}$. His clinical evolution confirms oxygen dependency between 12 and $15 \mathrm{~L} / \mathrm{min}$ with high concentration mask. Mr. P is transferred to the rehabilitation unit on April 4, 2020. Mr. P lives alone in his house with a bedroom on the first floor. He is able to walk without technical support, both inside and outside. During the examination, Mr. P clearly expresses that he wants to go back at home once he regained his previous functional level. A significant fear of falling is observed, measured at 15/ 28 with the short FES [5]. Mr. P also indicates that he fell twice in 2019, when walking in his garden, and explains that he had difficulties getting up from the floor. 


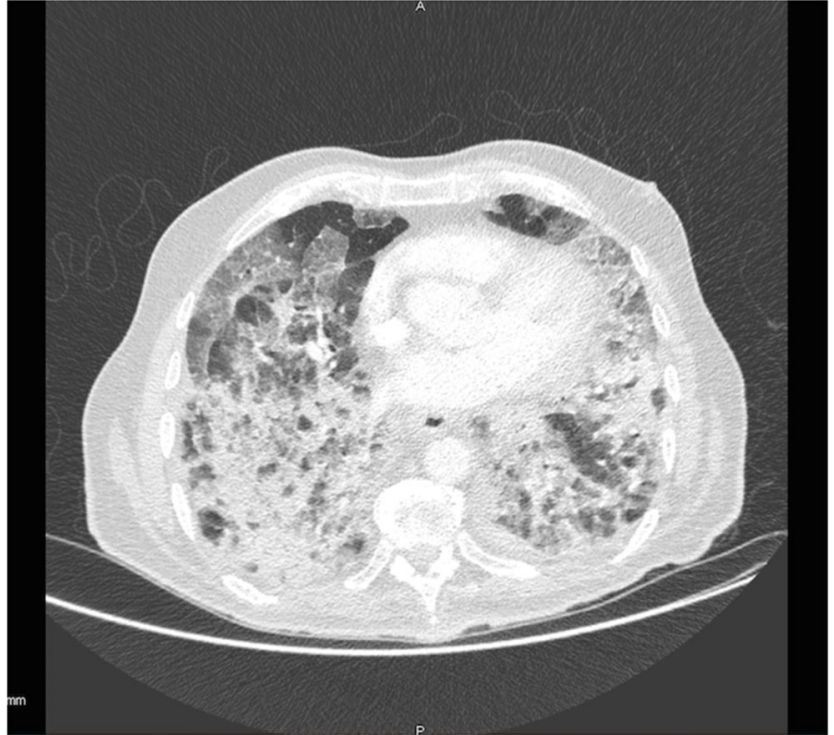

Fig. 1 Thoracic scan showing the typical ground-glass opacities

About medical treatment, the therapeutic drugs related to the COVID-19 affection were

- Plaquenil $400 \mathrm{mg}$ in the morning and evening on March 31, 2020. Then the plaquenil was prescribed only in the morning for 9 days.

- Methylprednisolone (corticoid) $20 \mathrm{mg}$ on April 6, 2020 and $100 \mathrm{mg}$ on April 7, 2020.

- Tolicizumab $500 \mathrm{mg}$ on April 6, 2020 and $500 \mathrm{mg}$ on April 9, 2020.
- Augmentin 1 g 3 times a day (morning, noon, and evening) from April 26, 2020 to May 3, 2020.

Mr. P also has an anti-coagulant treatment: Lovenox $7 \mathrm{ml}$ (7000 UI). This drug is administered subcutaneously every $24 \mathrm{~h}$ starting March 31, 2020. From April 8, 2020, the drug is administered over $12 \mathrm{~h}$.

Regarding comorbidities, Mr. P's treatment included the following:

- Furosemide (40 $\mathrm{mg}$ ) by direct intravenous injection every $24 \mathrm{~h}$ (in the morning) on April 7-8, 2020. This drug was introduced due to edema in the lower limbs.

- Kardegic 75.

- Perindopril (2 mg) morning and evening then decreased to only in the morning from April 20 onward.

In addition, two indexes of comorbidity, the Cumulative Illness Rating Scale (CIRS) (Table 1) and Charlson Comorbidity Index (Table 2), were carried out.

\section{Diagnostic Assessment}

We conducted the evaluation using a two-fold analysis. First, we evaluated the deficiencies linked with the COVID-19 infection and the associated ARDS, using a specific COVID-19 aggregation of scales. Next, we targeted the patient's motor function using the Frail'BESTest [6] so as to guide the clinical reasoning.

Table 1 Cumulative Illness Rating Scale (CIRS)

\begin{tabular}{lllll}
\hline System & $\begin{array}{l}\text { No problem } \\
(=0 \text { points })\end{array}$ & $\begin{array}{l}\text { Light problem } \\
(=1 \text { point })\end{array}$ & $\begin{array}{l}\text { Moderate problem } \\
(=2 \text { points })\end{array}$ & $\begin{array}{l}\text { Severe problem } \\
(=3 \text { points })\end{array}$ \\
\hline Cardiac & & 1 \\
High blood pressure & 0 & 1 \\
Vascular and hematopoietic & 0 & 1 \\
Respiratory & & \\
Eyes, ears, nose, throat, and larynx $)$ & \\
Upper gastrointestinal & 0 & \\
Lower gastrointestinal & 0 & \\
Liver, pancreas, and biliary & 0 & \\
Renal & 0 & 1 \\
Genitourinary & 0 & \\
Musculoskeletal and skin & 0 & \\
Neurologic & 0 & \\
Endocrine and breast & 0 & \\
Psychiatric illness & &
\end{tabular}

Cumulative Illness Rating Scale score $=4$ 
Table 2 Charlson comorbidity index

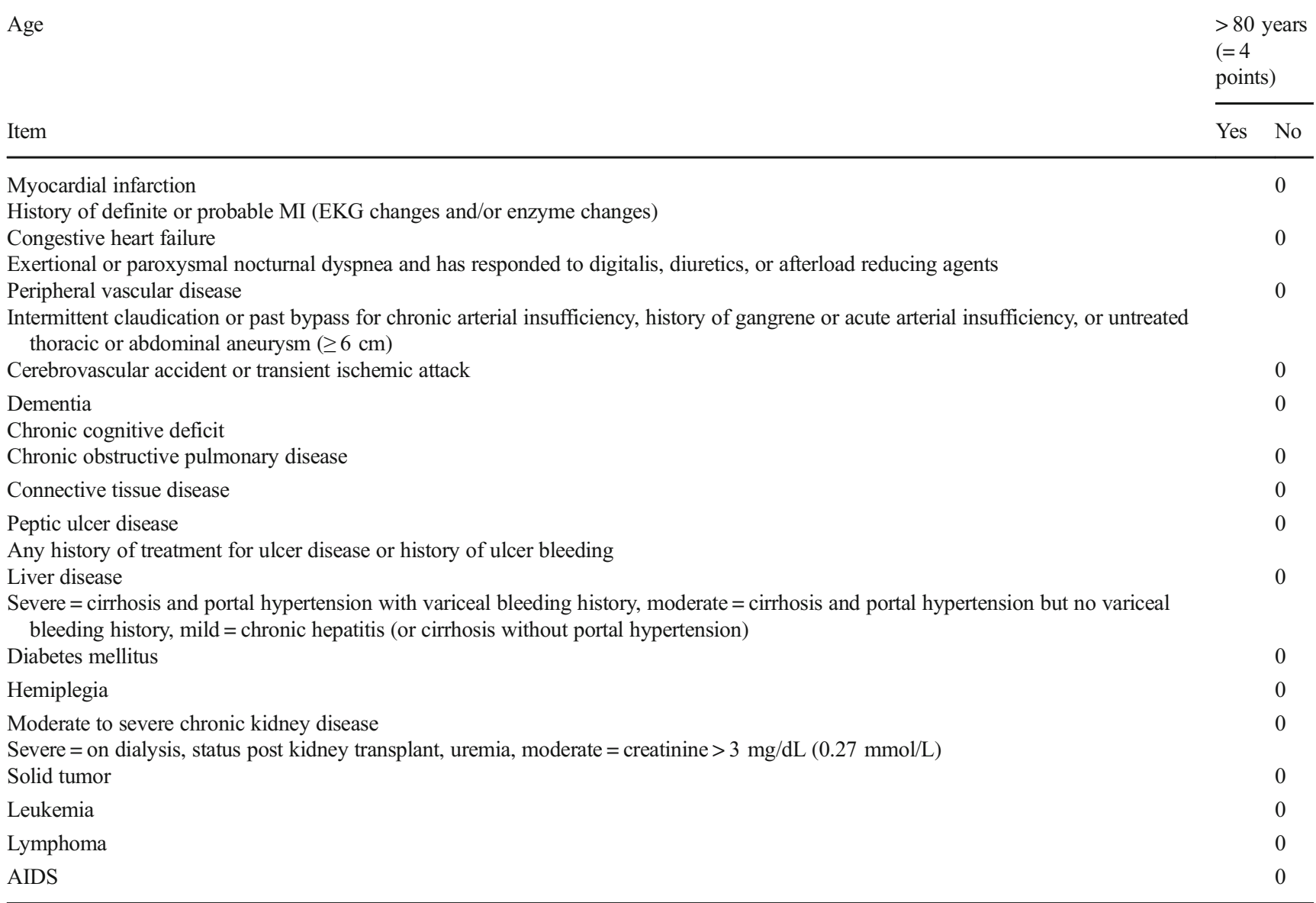

Charlson comorbidity index score $=4$

\section{Level 1: the Specific COVID-19 Evaluation}

Faced with the heterogeneity of COVID-19 clinical pictures, we tried to propose a global summary that includes several clinical examinations. The available literature $[7,8]$ notes a typical pulmonary deficiency associated with several new clinical scripts (ARDS, psychomotor disadaptation syndrome, acquired pneumopathy, acquired neuromyopathy, etc.). The scales were aggregated using a transdisciplinary rehabilitation approach to screen all the important aspects resulting from the infection. Tests were retained for their usability, reliability, and validity.

- Social and behavioral functions are evaluated with the RAMSAY score [9] and the RASS scale [10].

- Some items from the Hamilton scale (HDRS) are used to measure the psychological and emotional states [11].

- The simplified cardiac and respiratory evaluation allows us to measure the usual parameters with the mMRC dyspnea scale [12] and the Borg scale [13]. The peak cough flow rate (PCFr) is also measured $[14,15]$.

- In accordance with the loss of mass frequently described [8], the body mass index is noted. Swallowing function is evaluated with simple tests.

- Frailty detection is based on several tests showing good sensitivity: the gait speed measure [16], the chair test in $1 \mathrm{~min}$ [17], the functional reach test [18], and the grip strength test [19].

- Neuromotor functions are evaluated by the PFIT score [20] and the MMRC [21, 22]. A few items from the Mini Motor Test [23] and the BESTest [24] allow a global view of the patient.

- A binary analysis of statesthesia and tact are proposed, in addition to the other senses.

- Regarding sensitivity, a double assessment including statesthesia and touch [25] is done.

The evaluation synthesis of Mr. P is featured in Fig. $2 \mathrm{a}$ and $\mathrm{b}$. 


\begin{tabular}{|c|c|c|}
\hline \multicolumn{3}{|l|}{$\begin{array}{l}\text { Last name - First name: Mr P } 93 \text { years old } \\
\text { Medical / Physiotherapy prescription: physical therapy for patient with Covid-19 infection } \\
\text { Antecedents: high blood pressure / narrow lumbar canal / prostate adenoma } \\
\text { History of the disease: Covid-19 infection } \\
\text { COVID-19: } \otimes \text { Confirmed } \square \text { Strong suspicion } \square \text { Low suspicion } \square \text { Cured } \square \text { Healthy carrier } \\
\text { Evaluation achieved the: } 27 / 04 / 2020 \text { by BRIKA Marine (physiotherapist) }\end{array}$} \\
\hline \multicolumn{3}{|l|}{$\begin{array}{ll}\text { Pain: VAS 1: NA } / 10 ; \text { localisation: NA } & \text {; Vas 2: NA } \\
\text { Quality: NA } \quad \text {; Schedule: NA localisation: NA } & \text {; Duration / period: NA } \\
\text { Aggravating factors: NA } & \text {; Relieving factors: NA }\end{array}$} \\
\hline \multirow{2}{*}{\multicolumn{3}{|c|}{$\begin{array}{l}\text { Preliminary evaluation of cognitive, social and beha } \\
\text { Comment: no cognitive disorder } \\
\text { Vigilance: } 囚 Y \text { Yes } \square \text { No Cooperation: } ₫ Y \text { Yes } \square \text { No C } \\
\text { Agitation: } \square \text { Yes } \bigotimes \text { No MoCA: grade: NA/30 }\end{array}$}} \\
\hline & & \\
\hline \multicolumn{3}{|l|}{ צY } \\
\hline \\
\hline & 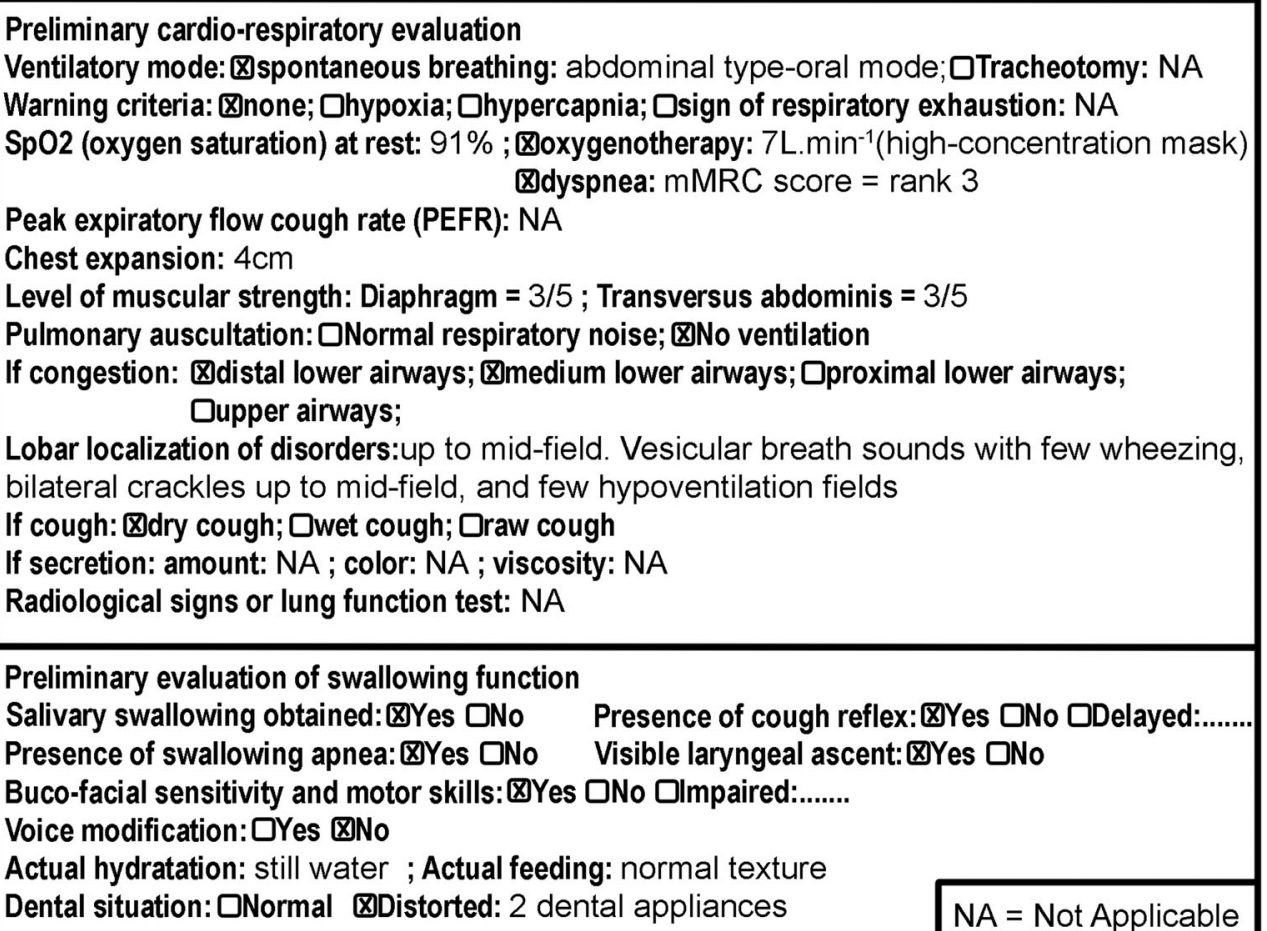 \\
\hline
\end{tabular}

Fig. 2 a Part one of specific COVID-19 evaluation, b part two of specific COVID-19 evaluation, and $\mathbf{c}$ part three of specific COVID-19 evaluation

\section{Level 2: Reasoning with the Frail'BESTest}

The Frail'BESTest has been developed to make it possible to include frail older adults in systemic evaluations [6]. Therapists can therefore directly manage therapeutic intervention for different types of balance deficiencies. Overall, six sub-systems have been addressed: (1) anticipations, (2) reactions, (3) locomotion, (4) sensorial orientation, (5) biomechanical constraints, and (6) asymmetric gait.

\section{Diagnosis}

Mr. P, a 93-year-old patient, presents with a respiratory dysfunction linked to a COVID-19 infection (saturation at 91\% 
Preliminary assessment of physical frailty

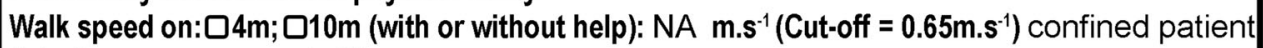
Grip force measurement: 36

One $\min$ Sit to Stand Test: 8 with armrests(Capacities: $<12$ degraded; $12<X<19$ limited; $>19$ normal)

$\mathrm{CF}=101 / \mathrm{min}-\mathrm{RF}=24 / \mathrm{min}-\mathrm{SpO}_{2}$ before test $=91 \%-\mathrm{SpO}_{2}$ after test $=85 \%$

$\mathrm{SpO}_{2}$ before walking in room $=90 \%-\mathrm{SpO}_{2}$ after walking in room $=84 \%$

Oxygenotherapy has should be increased by $1 \mathrm{~L}\left(=8 \mathrm{~L} \cdot \mathrm{min}^{-1}\right)$

FRT $=20 \mathrm{~cm}$ (if $<15 \mathrm{~cm}$ or $15<X<25$ : risk of fall);

Falls during the last 6 months: $\bigotimes Y$ Yes $\square$ No QUnknown

Preliminary functional and neuromotor evaluation

PFIT-scored: 5.9/10; main factors: low walking speed (rank1)

Preserved cranial nerve pairs: $囚$ Yes $\square$ No

mMRC: $44 / 60$ ( $<48$ evocative of NMAR); main factor: decreased strength in lower limb muscles

sit to stand transfers $\bigotimes Y$ Yes $\square$ No; seated balance $\otimes Y e s \square$ No ; standing position $\bigotimes Y$ Yes $\square$ No

U-turns $\otimes Y$ Yes $\square$ No

BESTest III-10: Mounted on tiptoe: $\square 3 \quad \otimes 2 \square 1 \quad \square 0$

Without human or material assistance: $\square$ walk; $囚$ get dress; $\square$ to take a shower; $\bowtie$ eat; $\square$ others:........

If assisstance, specify: Rollator (dynamic instability without) - human assisstance to wash

Vesico-sphincteric affections: $\square$ Yes $\otimes$ No

Musculoskeletal disorders: $\square$ Cervical spine; $\square$ Shoulders; $\square$ Others: NA

Preliminary sensitivity assessment

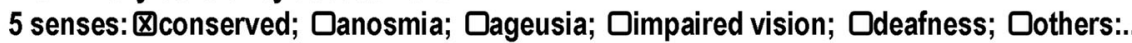

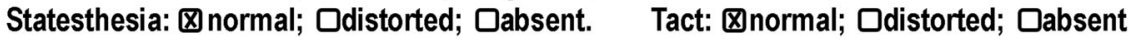
Comments:

Preliminary educational diagnosis

Carried out: $\otimes a t$ the start of the day; $\square$ at the end of the day

Disease: patient says he is 'affected by COVID'

Treatments (medical \& paramedical): patient don't know his medical treatment patient verbalizes 'being aware of needing oxygen'

Physical activity \& selh rehabilitation: not list in the way of self-rehabilitation patient verbalizes 'the importance of physiotherapy' due to his major asthenia

NA $=$ Not Applicable

\begin{tabular}{|c|c|c|}
\hline Summary of the asses & abilitative diagnosis - catego & tion: \\
\hline $\begin{array}{l}\square \text { Pain patient; } \\
\square \text { Alteration of the skin c }\end{array}$ & $\begin{array}{l}\square \text { Impairment } \\
\otimes \text { Altered psy }\end{array}$ & $\begin{array}{l}\text { f social and behavioral functions; } \\
\text { hological and emotionnal functions; }\end{array}$ \\
\hline $\begin{array}{l}\text { 口Bronchial congestion; } \\
\text { 冈Stress mismatch; }\end{array}$ & $\begin{array}{l}\text { 囚Hematosis disorder; } \\
\text { 口Alteration of oral functions; }\end{array}$ & $\begin{array}{l}\text { 囚Impaired ventilation mechanics; } \\
\text { Dlmpaired swallowing functions; }\end{array}$ \\
\hline 囚Physical frailty; & 口Altered sensitivities; & mpaired neuro-locomotor functions; \\
\hline Dimpairment of function & abilities; & eutic education; \\
\hline
\end{tabular}

Assessment of dysfunctions (can be checked in combination): Cardio-respiratory disease: 囚Yes $\square$ No; if yes: 囚Major $\square$ Minor Oral/dysphagic dysfunction: $\square$ Yes $\bigotimes$ No; if yes: $\square$ Major $\square$ Minor Frailty: 囚Yes $\square$ No; if yes: $\otimes$ Major $\square$ Minor Neuro-locomotor disorders: $\otimes Y e s \square$ No; if yes: खMajor $\square$ Minor Functionnal disorders: $囚 Y$ Yes $\square$ No; if yes: $\square$ Major 囚Minor Sensitive dysfunctions: $\square$ Yes $\otimes N$; ; if yes: $\square$ Major $\square$ Minor

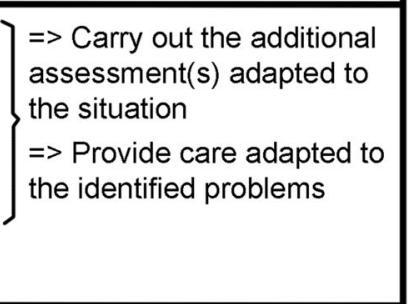

Fig. 2 (continued) 
with $7 \mathrm{~L}$ of oxygen supplementation), subsequent effort incapacity, and postural-motor deficiencies. Motor automatisms are impaired, and several articular and muscular constraints remain. Mr. P seems enlisted in a frailty process, leading to increased dependency, an impossibility to return home, and relative social isolation.

\section{Therapeutic Intervention}

The protocol was carried out in accordance with legal and international requirements (Declaration of Helsinki, 1964). Mr. P was informed about the published project and gave his written consent before the evaluation.

Mr. P followed a rehabilitation program which primarily included physical therapy and nutritional monitoring. He received one session of physical therapy per day. This session lasted on average of $30 \mathrm{~min}$. Considering the physiotherapeutic diagnosis of Mr. P, as well as the agespecific lung physiology of the patient [26], some cardiopulmonary rehabilitation exercises allowing both the maintenance of ventilator functions and the improvement of hematosis can be proposed. During all of these exercises, precautions, red flags, and stop criteria indicated in the HAS Quick Response [27] should be followed.

The next paragraph will show the aims and exercise samples that have been proposed to Mr. P. We would like to improve both the transverse abdominis and the diaphragm via active, functional, and resistive treatments including threshold systems, hypopressive exercise, and functional ventilation during movement [28-30]. In order to limit physiological impairment, some exercises including thoracic movement with the arms, chest, and spine mobility are introduced during global therapy in both directions: inhale and exhale $[31,32]$. In order to improve oxygenation and prevent congestion, ventilation should be harmonized throughout the lung territories, and mucociliary clearance should be promoted. Thus, the treatment involves high-volume ventilation-type work that includes tele-inspiratory holds, while avoiding specific collapses associated with senescence. For example, EDIC, ITLA (Inspiratory Technical for Lifting Atelectasis), Elpr, and ACBTtype exercises with open glottis are proposed [33, 34]. Concerning rehabilitation with effort, it is necessary to increase the ventilatory threshold in order to improve muscular function and decrease dyspnea. This will also improve hematosis and oxidative metabolism. An early and progressive cardiopulmonary rehabilitation program is established and based on the Borg scale [35, 36]. For Mr. P, it includes optimal loading, aerobic work measured by paliers, as well as endurance. This program mainly uses functional exercises such as treadmill walking (between 60 and $80 \%$ of the TM6 or the chair-test or

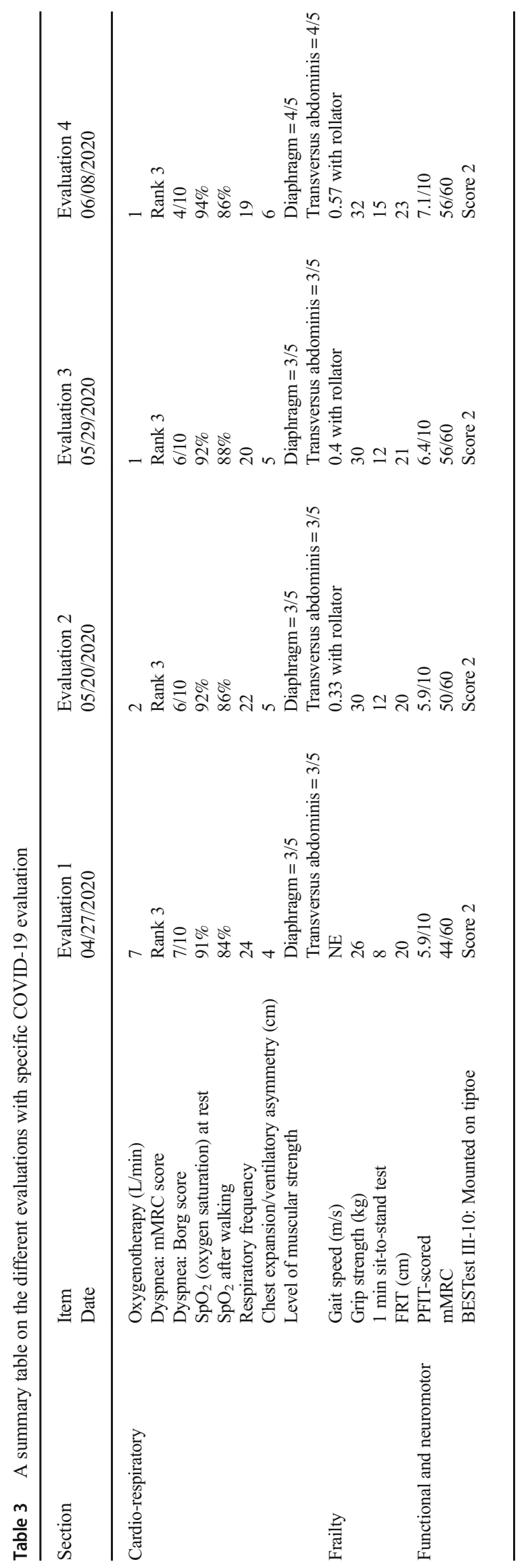


top toes test) [37]. It also seems important to prevent dysphagia in the medium term and to optimize the use of the functions of the nose (to warm, filter, and humidify the air). So, nasal ventilation and correction of the tongue position is essential. For example, mindless nasal ventilation and the tongue palate position is monitored, and lingual resistive exercise and sensitive work are proposed. In a final perspective on the patient's autonomy, throughout the rehabilitation process, education on the perception of effort, use of the Borg scale, the patient's self-assessment of his respiratory capacities, and the criteria of alerts are all carried out [38].

On the other hand, in connection with the systemic evaluation of the balance function and motor frailty of Mr. P, several sensory-motor exercises are proposed. To improve the efficiency of postural-movement coordination, self-paced perturbations of balance were worked on with speed and variability [39]. For example, Mr. P had to reach a colored target on the ground as quickly as possible once the physiotherapist indicated the color he has to hit. To reactivate postural adaptations and fall avoidance reactions, Mr. P performs exercises that work on extrinsic imbalances (unpredictable balance perturbation) [40]. For example, Mr. P had to react to manual pushes from the physiotherapist. In order to improve muscular power, functional muscular exercises were performed in a closed chain and under a time constraint [41]. For example, Mr. P had to go up and down a step to the beat of a metronome. In order to regain physiological ankle mobility and enhance the rolling of feet when walking, active mobilization exercises were carried out during physiotherapy sessions and also by the patient independently in his room [42]. To reduce podal dependency, Mr. P performed static and dynamic balance exercises on different ground textures (e.g., standing on foam, walking on a mat, walking outside in the grass). Finally, exercises incorporating the work of spatial and temporal parameters of walking and changes of direction were carried out. These exercises were aimed at improving walking kinetics and would contribute to the evolution of help with technical walking.

\section{Follow-up and Outcomes}

The four assessments performed by the specific COVID-19 evaluation showed an overall improvement of the patient in several functions. In terms of psychological and emotional state, the anxiety with regard to oxygen dependence disappeared. Indeed, during the initial assessment, the patient had $7 \mathrm{~L}$ of oxygen in the high-concentration face mask. During the final evaluation, he had only $1 \mathrm{~L}$ of oxygen left in the nasal cannula. Pulmonary auscultation, which initially revealed a lack of ventilation associated with congestion of the middle and distal airways, also improved. Final auscultation was evaluated without particularities. The assessment of cognitive and behavioral functions remained unchanged over the course of the four assessments. Initial clinical observations did not show impairment of these functions. The initial preliminary assessment of the vascular and cutaneous system had shown the presence of a stage 1 pressure ulcer (as per the National Pressure Ulcer Advisory Panel Stage Classification) behind the ears due to the oxygen mask. Upon final evaluation, the pressure ulcer was no longer present. No vascular disorders occurred during the hospitalization. Moreover, there was no significant change in swallowing function, as Mr. P did not present any swallowing problems.

Changes to the scores of quantitative outcomes of the different functions are summarized in Table 3 .

The four Frail'BESTest assessments show an improvement in the score of some subsystems. The results are summarized in Table 4.

Table 4 A summary table on the different evaluations with Frail'BESTest

\begin{tabular}{lllll}
\hline Frail'BESTest & $\begin{array}{l}\text { Initial } \\
\text { evaluation }\end{array}$ & $\begin{array}{l}\text { Intermediate evaluation (number } \\
\text { one) }\end{array}$ & $\begin{array}{l}\text { Intermediate evaluation (number } \\
\text { two) }\end{array}$ & Final evaluation \\
\hline Date & $04 / 27 / 2020$ & $05 / 20 / 2020$ & $05 / 29 / 2020$ & $06 / 08 / 2020$ \\
System A: anticipations & 3 & 3 & 3 & 4 \\
System B: reactions & 0 & 0 & 0 & 2 \\
System C: locomotion & $\mathrm{NE}$ & 1 & 2 & 2 \\
System D: sensory orientation & 2 & 2 & 2 & 4 \\
System E: biomechanical & 2 & 3 & 3 & 4 \\
$\quad$ constraints & 4 & 4 & 14 & 18 \\
System F: gait symmetry & 11 & 13 & 0.4 with rollator \\
Total score & NE & 0.33 with rollator & rollator \\
Gait speed $(\mathrm{m} / \mathrm{s})$ & & & & \\
& & &
\end{tabular}




\section{Discussion and Conclusions}

This case allows us to underline the global approach that is necessary in a geriatric rehabilitation context associated with the COVID-19 infection. Although the long-term follow-up is not yet available, it seems important to continue the clinical pictures description associated with this virus in order to better organize rehabilitation strategies. Indeed, the rehabilitation process represents the other challenge of the pandemic situation in several countries characterized by a high proportion of frail patients [43]. In our opinion, it is important to understand that the issue is not only to rescue a patient from their acute respiratory problem, but more so to prevent the functional dependency associated with the infection's consequences, especially in intensive care units where chronic diseases are frequently acquired.

Mr. P was probably lucky to return home with a high level of independency. His age and relative frailty were, at the beginning, considered to be bad prognosis factors. As is common in geriatric rehabilitation, age is not only a question of numbers. In the same manner, frailty should not be questioned as an independence level, but more in terms of functional reserves. Mr. P presented sufficient functional reserves, although he was certainly frail upon arriving at the hospital.

Several papers have described the physiotherapy associated with the COVID-19 infection since the pandemic began. A lot of them describe adult patients, often aged up to 65 years, considering respiratory or pulmonary rehabilitation. Strength recommendations are available to manage these COVID-19 patients [8]. However, age and frailty are key factors to consider when targeting the needs of these patients, and all of our health systems should be adapted to the second wave of the pandemic situation: the rehabilitation wave [44].

Although a higher vulnerability of geriatric patients has been observed, the literature on aged COVID-19 patients has remained very scarce. A few studies have already adequately targeted these patients and described interesting clinical pictures and associated medical treatments [45]. However, to our knowledge, this is the first case report highlighting the rehabilitation process with an aged COVID-19 patient who needs to be seen also as a respiratory case and as a frail patient.

Acknowledgments The authors thank Dr. Julie Caissutti for her precious help.

\section{Compliance with Ethical Standards}

Conflict of Interest The authors declare that they have no conflict of interest.

Ethical Approval The protocol performed in this case report is in accordance with the ethical standards of the institutional and/or national research committee and with the 1964 Helsinki declaration and its later amendments or comparable ethical standards.
Informed Consent Mr. P was informed about the publication of the project and gave his consent.

\section{References}

1. Promislow DEL. A Geroscience perspective on COVID-19 mortality. J Gerontol A Biol Sci Med Sci. 2020;75(9):e30-3. https://doi. org/10.1093/gerona/glaa094.

2. Silva-Obregón JA, Quintana-Díaz M, Saboya-Sánchez S, MarianCrespo C, Romera-Ortega MÁ, Chamorro-Jambrina C, et al. Frailty as a predictor of short- and long-term mortality in critically ill older medical patients. J Crit Care. 2020;55:79-85. https://doi.org/10. 1016/j.jcrc.2019.10.018.

3. Simpson R, Robinson L. Rehabilitation after critical illness in people with COVID-19 infection. Am J Phys Med Rehabil. 2020;99(6):470-4. https://doi.org/10.1097/PHM. 0000000000001443 .

4. Ceravolo MG, de Sire A, Andrenelli E, Negrini F, Negrini S. Systematic rapid "living" review on rehabilitation needs due to COVID-19: update to March 31st, 2020. Eur J Phys Rehabil Med. 2020;56(3):347-53. https://doi.org/10.23736/S1973-9087. 20.06329-7.

5. Hauer KA, Kempen GIJM, Schwenk M, Yardley L, Beyer N, Todd $\mathrm{C}$, et al. Validity and sensitivity to change of the falls efficacy scales international to assess fear of falling in older adults with and without cognitive impairment. Gerontology. 2011;57(5):462-72. https://doi.org/10.1159/000320054.

6. Kubicki A, Brika M, Coquisart L, Basile G, Laroche D, Mourey F. The Frail'BESTest. An adaptation of the "Balance Evaluation System Test" for frail older adults. Description, internal consistency and inter-rater reliability. CIA. 2020;15:1249-1262

7. Lescure F-X, Bouadma L, Nguyen D, Parisey M, Wicky PH, Behillil S, et al. Clinical and virological data of the first cases of COVID-19 in Europe: a case series. Lancet Infect Dis. 2020;20(6): 697-706. https://doi.org/10.1016/S1473-3099(20)30200-0.

8. Thomas P, Baldwin C, Bissett B, Boden I, Gosselink R, Granger $\mathrm{CL}$, et al. Physiotherapy management for COVID-19 in the acute hospital setting: clinical practice recommendations. Aust J Phys. 2020;66(2):73-82. https://doi.org/10.1016/j.jphys.2020.03.011.

9. Carrasco G. Instruments for monitoring intensive care unit sedation. Crit Care. 2000;4(4):217-25. https://doi.org/10.1186/cc697.

10. Ely EW, Truman B, Shintani A, Thomason JWW, Wheeler AP, Gordon S, et al. Monitoring sedation status over time in ICU patients: reliability and validity of the Richmond agitation-sedation scale (RASS). JAMA. 2003;289(22):2983-91. https://doi.org/10. 1001/jama.289.22.2983.

11. Carrozzino D, Patierno C, Fava GA, Guidi J. The Hamilton rating scales for depression: a critical review of clinimetric properties of different versions. Psychother Psychosom. 2020;89(3):133-50. https://doi.org/10.1159/000506879.

12. Munari AB, Gulart AA, Dos Santos K, Venâncio RS, Karloh M, Mayer AF. Modified Medical Research Council dyspnea scale in GOLD classification better reflects physical activities of daily living. Respir Care. 2018;63(1):77-85. https://doi.org/10.4187/ respcare.05636.

13. Borg GA. Psychophysical bases of perceived exertion. Med Sci Sports Exerc. 1982;14(5):377-81.

14. Bianchi C, Baiardi P, Khirani S, Cantarella G. Cough peak flow as a predictor of pulmonary morbidity in patients with dysphagia. Am J Phys Med Rehabil. 2012;91(9):783-8. https://doi.org/10.1097/ PHM.0b013e3182556701.

15. Kim J, Davenport P, Sapienza C. Effect of expiratory muscle strength training on elderly cough function. Arch Gerontol 
Geriatr. 2009;48(3):361-6. https://doi.org/10.1016/j.archger.2008. 03.006 .

16. Middleton A, Fritz SL, Lusardi M. Walking speed: the functional vital sign. J Aging Phys Act. 2015;23(2):314-22. https://doi.org/10. 1123/japa.2013-0236.

17. Puhan MA, Siebeling L, Zoller M, Muggensturm P, ter Riet G. Simple functional performance tests and mortality in COPD. Eur Respir J. 2013;42(4):956-63. https://doi.org/10.1183/09031936. 00131612.

18. Scena S, Steindler R, Ceci M, Zuccaro SM, Carmeli E. Computerized functional reach test to measure balance stability in elderly patients with neurological disorders. J Clin Med Res. 2016;8(10):715-20. https://doi.org/10.14740/jocmr2652w.

19. Dodds RM, Syddall HE, Cooper R, Benzeval M, Deary IJ, Dennison EM, et al. Grip strength across the life course: normative data from twelve British studies. PLoS One. 2014;9(12):e113637. https://doi.org/10.1371/journal.pone.0113637.

20. Denehy L, de Morton NA, Skinner EH, Edbrooke L, Haines K, Warrillow S, et al. A physical function test for use in the intensive care unit: validity, responsiveness, and predictive utility of the physical function ICU test (scored). Phys Ther. 2013;93(12): 1636-45. https://doi.org/10.2522/ptj.20120310.

21. Jolley SE, Bunnell AE, Hough CL. ICU-acquired weakness. Chest. 2016;150(5):1129-40. https://doi.org/10.1016/j.chest.2016.03.045.

22. Hermans G, Clerckx B, Vanhullebusch T, Segers J, Vanpee G, Robbeets $\mathrm{C}$, et al. Interobserver agreement of Medical Research Council sum-score and handgrip strength in the intensive care unit. Muscle Nerve. 2012;45(1):18-25. https://doi.org/10.1002/mus. 22219.

23. Mourey F, Camus A, d'Athis P, Blanchon MA, Martin-Hunyadi C, Rekeneire N, et al. Mini motor test: a clinical test for rehabilitation of patients showing psychomotor disadaptation syndrome (PDS). Arch Gerontol Geriatr. 2005;40(2):201-11. https://doi.org/10. 1016/j.archger.2004.08.004.

24. Horak FB, Wrisley DM, Frank J. The balance evaluation systems test (BESTest) to differentiate balance deficits. Phys Ther. 2009;89(5):484-98. https://doi.org/10.2522/ptj.20080071.

25. Baig AM. Neurological manifestations in COVID-19 caused by SARS-CoV-2. CNS Neurosci Ther. 2020;26(5):499-501. https:// doi.org/10.1111/cns.13372.

26. Skloot GS. The effects of aging on lung structure and function. Clin Geriatr Med. 2017;33(4):447-57. https://doi.org/10.1016/j.cger. 2017.06.001.

27. Prise en charge des patients post-COVID-19 en médecine physique et de réadaptation (MPR), en soins de suite et de réadaptation (SSR), et retour à domicile. Haute Autorité de Santé. Accessed July 27, 2020. https://www.has-sante.fr/jcms/p_3179826/fr/priseen-charge-des-patients-post-covid-19-en-medecine-physique-etde-readaptation-mpr-en-soins-de-suite-et-de-readaptation-ssr-etretour-a-domicile.

28. Babcock MA, Pegelow DF, Johnson BD, Dempsey JA. Aerobic fitness effects on exercise-induced low-frequency diaphragm fatigue. J Appl Physiol. 1996;81(5):2156-64. https://doi.org/10. 1152/jappl.1996.81.5.2156.

29. Fulton I, McEvoy M, Pieterse J, Williams M, Thoirs K, Petkov J. Transversus abdominis: changes in thickness during the unsupported upper limb exercise test in older adults. Physiother Theory Pract. 2009;25(8):523-32. https://doi.org/10.3109/09593980802665023.

30. O'Kroy JA, Coast R. Effects of flow and resistive training on respiratory muscle endurance and strength. RES. 1993;60(5):279-83. https://doi.org/10.1159/000196216.

31. Han JW, Kim YM. Effect of breathing exercises combined with dynamic upper extremity exercises on the pulmonary function of young adults. J Back Musculoskelet Rehabil. 2018;31(2):405-9. https://doi.org/10.3233/BMR-170823.

32. Petrofsky JS, Cuneo M, Dial R, Pawley AK, Hill J. Core strengthening and balance in the geriatric population. J Appl Res. 2005;5(3):11.

33. Lewis LK, Williams MT, Olds TS. The active cycle of breathing technique: a systematic review and meta-analysis. Respir Med. 2012;106(2):155-72. https://doi.org/10.1016/j.rmed.2011.10.014.

34. Pryor JA. Physiotherapy for airway clearance in adults. Eur Respir J. 1999;14(6):1418-24. https://doi.org/10.1183/09031936.99. 14614189.

35. Svedahl K, MacIntosh BR. Anaerobic threshold: the concept and methods of measurement. Can J Appl Physiol. 2003;28(2):299 323. https://doi.org/10.1139/h03-023.

36. Alexander JL, Phillips WT, Wagner CL. The effect of strength training on functional fitness in older patients with chronic lung disease enrolled in pulmonary rehabilitation. Rehabil Nurs. 2008;33(3):91-7. https://doi.org/10.1002/j.2048-7940.2008. tb00211.x.

37. Opasich C, Patrignani A, Mazza A, Gualco A, Cobelli F, Pinna GD. An elderly-centered, personalized, physiotherapy program early after cardiac surgery. Eur J Cardiovasc Prev Rehabil. 2010;17(5): 582-7. https://doi.org/10.1097/HJR.0b013e3283394977.

38. O'Donnell DE, Chau LK, Webb KA. Qualitative aspects of exertional dyspnea in patients with interstitial lung disease. J Appl Physiol. 1998;84(6):2000-9. https://doi.org/10.1152/jappl.1998. 84.6.2000.

39. Jagdhane S, Kanekar N, Aruin AS. The effect of a four-week balance training program on anticipatory postural adjustments in older adults: a pilot feasibility study. Curr Aging Sci. 2016;9(4):295-300. https://doi.org/10.2174/1874609809666160413113443.

40. Mansfield A, Peters AL, Liu BA, Maki BE. Effect of a perturbationbased balance training program on compensatory stepping and grasping reactions in older adults: a randomized controlled trial. Phys Ther. 2010;90(4):476-91. https://doi.org/10.2522/ptj. 20090070.

41. Foldvari M, Clark M, Laviolette LC, Bernstein MA, Kaliton D, Castaneda $\mathrm{C}$, et al. Association of muscle power with functional status in community-dwelling elderly women. J Gerontol A Biol Sci Med Sci. 2000;55(4):M192-9. https://doi.org/10.1093/gerona/ 55.4.m192.

42. Smajla D, García-Ramos A, Tomazin K, Strojnik V. Selective effect of static stretching, concentric contractions, and a one-leg balance task on ankle motion sense in young and older adults. Gait Posture. 2019;71:1-6. https://doi.org/10.1016/j.gaitpost.2019.04. 006.

43. Özkeskin M, Elibol N, Bakırhan S. Risk of COVID-19 disease in the elderly population and physiotherapy. Physiotherapy. 2020;108:76-7. https://doi.org/10.1016/j.physio.2020.05.003.

44. De Biase S, Cook L, Skelton DA, Witham M, Ten Hove R. The COVID-19 rehabilitation pandemic. Age Ageing. 2020;49(5):696700. https://doi.org/10.1093/ageing/afaa1 18 .

45. Bentivegna E, Luciani M, Spuntarelli V, Speranza ML, Guerritore L, Sentimentale A, et al. Extremely severe case of COVID-19 pneumonia recovered despite bad prognostic indicators: a didactic report. SN Compr Clin Med. 2020;2(8):1204-7. https://doi.org/10. 1007/s42399-020-00383-0.

Publisher's Note Springer Nature remains neutral with regard to jurisdictional claims in published maps and institutional affiliations. 